\title{
Bilgisayarlı tomografilerde hastanın aldığı efektif radyasyon dozunun belirlenmesi
}

\author{
Lütfi İhsan KURU, Osman GÜNAY*, Havva PALACI, Onur YARAR \\ İstanbul Okan Üniversitesi, Sağllk Hizmetleri Meslek Yüksek Okulu, Tuzla İstanbul \\ Geliş Tarihi (Recived Date): 14.11.2018 \\ Kabul Tarihi (Accepted Date): 22.03.2019
}

\section{Özet}

Son yıllarda bilgisayarlı tomografi (BT) kullanımı hastalara tanı koyabilme açısından vazgeçilmez bir görüntüleme teknolojisi olduğu tüm otoritelerce kabul edilmekle birlikte BT kullanımının aşırıya kaçtı̆̆ da kabul edilmektedir. Çok hızlı olan çok kesitli BT cihazlarının kullanıma girmesi ile çocuk hastalarda anestezi uygulamasına gerek kalmadan tetkikleri yapılabilmiştir. Bu durum da çocuk hastalarda BT kullanımında aşırı artışa sebep olmuştur. Yetişkinlerde ise aşırı artışın büyük bir bölümünü asemptomatik hastalarda BT kolonoskopi, kardiyak anjiyo ve tüm vücut tarama gibi tetkikler oluşturmaktadır. BT kullanımının bu kadar aşırı olması da beraberinde radyasyona maruz kalma riskini artırmaktadır. Bu çalışmada, BT tetkiklerinde hastanın maruz kaldığ gerçek radyasyon dozunun ortaya konması amacıyla BT cihazından okunan değer ile gerçekte hastanın aldı ̆̆ radyasyon dozunun karşılaştırılması yapılmıştır. Bunun için 25 hasta üzerine termolüminesans (TLD) detektörleri yerleştirilmiştir. BT cihazından okunan radyasyon dozu ile TLD kristallerinden okunan radyasyon dozu arasında \%4 farklıllk olduğu bulunmuştur.

Anahtar kelimeler: Bilgisayarlı tomografi, TLD, X ışınları, ASIR.

Lütfi İhsan KURU, ihsan.kuru@ okan.edu.tr, http://orcid.org/0000-0002-7985-3182

* Osman GÜNAY, osman.gunay@ okan.edu.tr , http://orcid.org/0000-0003-0760-554X

Havva PALACI, havva.palaci@ okan.edu.tr, http://orcid.org/0000-0002-7985-3182

Onur YARAR, onur.yarar@ okan.edu.tr, http://orcid.org/0000-0002-9959-4333 


\title{
Determination of the effective radiation dose of the patient in computed tomography
}

\begin{abstract}
In recent years, the use of computed tomography $(C T)$ has been recognized by all authorities as an indispensable imaging technology for diagnosing patients. With the introduction of multislice CT devices that were very fast, the patients could be examined without the need for anesthesia. This has led to an excessive increase in the use of CT in pediatric patients. In adults, a large part of the excessive increase is observed in asymptomatic patients such as CT colonoscopy, cardiac angiography and whole body scan. The excessive use of CT increases the risk of exposure to radiation. In this study, in order to reveal the actual radiation dose that the patient was exposed to in the CT examinations, a comparison was made between the value obtained from the CT device and the radiation dose exposed to by the patient. Thermoluminescence (TLD) detectors were placed on 25 patients. It was found that there was a 4\% difference between the radiation dose read from the CT and the radiation dose from the TLD crystals.
\end{abstract}

Keywords: Computed Tomography, TLD, X-ray, ASIR.

\section{Giriş}

Çevresel sorunlar insanları fizyolojik ve psikolojik olarak sürekli etkilemektedir [1]. Bu sorunlardan bir tanesi de doğal radyasyon ve yapay yollardan elde edilen radyasyona maruz kalmadır [2-11]. Yapay yolla maruz kalınan radyasyon, nükleer reaktörlerden, parçacık hızlandırıcılardan, nükleer silah denemelerinden ve sağlık uygulamalarından kaynaklanmaktadır [12]. İnsanların sağlık uygulamalarından aldıkları radyasyon dozu diğer yapay kaynaklardan aldıkları radyasyon dozuna göre oldukça fazladır. İyonize radyasyon tüm canlıları etkilediği gibi insanları da etkilemektedir.

İyonize radyasyon insanlar üzerindeki etkisi somatik ve genetik etki olmak üzere iki ayrı kısımda incelenmektedir. Somatik etkiler, insanlardaki üreme hücreleri dışındaki etkileri kapsamaktadır. Somatik etkiler, deterministik etki ve stokastik etki olmak üzere iki ayrı sınıfa ayrılmaktadır. Radyasyonun insan üzerinde deterministik etki meydana getirebilmesi için, insanın yüksek dozda radyasyona maruz kalması gerekir. Deterministik etkide belirli bir eşik doz değeri vardır. Bu eşik doz değeri aşıldığında insanlarda radyasyonun deterministik etkisi ortaya çıkmaya başlar. İnsanlar düşük dozdaki radyasyona sürekli olarak maruz kaldığı zaman stokastik etkiler görülebilir. Stokastik etkiler için belirli bir eşik değeri yoktur. Düşük dozda bile, uzun süre radyasyona maruz kalındığında ortaya çıkan stokastik etkilerin bazıları, tiroid kanseri, akciğer kanseri ve lösemi olabilmektedir [13].

Röntgen tarafından keşfedilen $X$ 1şınları, günümüzde tıbbi görüntülemenin birçok alanında kullanılmaktadır. Tıp alanında X ışınlarının en klasik kullanım alanı klasik röntgen çekimlerinde ve bilgisayarlı tomografidedir. Bilgisayarlı tomografi (BT) 1970'li yıllarda tıpta teşhis amaçlı kullanılmaya başlanmıştır. Son yıllarda BT kullanımı çok hızlı bir şekilde artmıştır. Son 20 yılda bilgisayarlı tomografi kullanımı ABD de 20 kat, İngiltere'de ise yaklaşık 12 kat artmıştır [14]. Bu artıştaki en büyük etkenler, çekim 
tekniğinin hızlı bir şekilde gelişmiş olması ve klinik uygulamalardaki yaygınlığının artmış olmasıdır [15-16].

BT çekimlerinde en yüksek artışlardan bir tanesi de çocuk hastalardaki çekimlerdir. Çocuklarda BT çekim oranı farklı çalışmalarda farklı miktarlarda olduğu ifade edilmekte olup bu oran $\% 6$ ile $\% 11$ arasındadır. Çocuk hastalar üzerindeki BT çekimlerinin artışındaki en büyük nedenlerden bir tanesi çekim süresindeki azalmadan kaynaklanmaktadır. Yetişkinlerdeki, BT kullanımının büyük kısmı, tüm vücut tarama, akciğer tarama, BT kolonografi ve kardiyak taramadan meydana gelmektedir [17-19].

Geleneksel röntgen çekimlerine göre, BT çekimlerinde, hastanın aldığı radyasyon dozu oldukça fazladır. Geleneksel röntgen çekimlerinde akciğerin aldığı radyasyon dozu 0.02 $\mathrm{mSv}$ ile $0.15 \mathrm{mSv}$ arası değişirken eski tip BT cihazlarında toraks da ki doz miktarı yaklaşık $10 \mathrm{mSv}$ ile $20 \mathrm{mSv}$ arasında değişmektedir. Bu da hastaya verilen radyasyon dozunun, geleneksel röntgen görüntülemelerine göre 800 kat ile 1000 kat arasında değiştiğini göstermektedir [15]. Fakat günümüzde kullanılan çok kesitli BT cihazlarında bu oran yaklaşık olarak 100 ile 400 kat civarına kadar indirilmiştir.

Bilgisayarlı Tomografi tetkiklerinde, konvansiyonel röntgen tetkiklerine oranla çok daha fazla iyonizan radyasyona maruz kalınmaktadır. Bilgisayarlı tomografide hastanın almış olduğu radyasyonu dozunu etkileyen çok sayıda parametre vardır. Bunlardan bazıları, tüp voltajı, tüp akımı, hasta boyu ve ağırlığı, pitch değeri, kesit sayısı, kesit kalınlığıdır. BT çekimini etkileyen bu faktörler teknisyen, tekniker ve uzman radyolog tarafından çeşitli kriterlere göre değiştirilebilmektedir.

BT çekiminde radyasyon dozunu azaltmak amacıyla birçok program kullanılır. Bu programlardan bir tanesi de General Elektrik (GE) firmasının ürettiği ASIR (Uyarlamalı İstatistiksel Tekrarlanan Yeniden Yapılanma) programıdır. Bu program piksel gürültü standart sapmasında azaltma sağlayabilecek bir yapılandırma teknolojisidir. BT' de görüntünün kaliteli olması hastaya verilen radyasyon dozu ile orantılıdır. Hastaya düşük doz verilirse, gürültü artarak görüntü kalitesi düşer. ASIR programı otomatik mAs değerlerini düşürüp masa hızını da artırarak hastanın aldığı radyasyon dozunu oldukça düşürmektedir. ASIR programı bu gürültülü pikselleri seçerek yok eder ve geriye kalan net görüntüleri sisteme aktarır. Böylece daha düşük bir radyasyon dozuyla, kabul edilebilir net bir görüntü elde edilmiş olur.

Sonuç olarak BT'nin tanısal anlamda önemli tıbbi yararları olmasına karşın iyonizan radyasyonla ilişkili kanser oluşumunda çok büyük bir riski bulunmaktadır. BT tetkiki muhakkak gerekli ise BT kullanılırken otomatik doz kontrol yöntemleri, cihazlarda bulunan doz azaltıcı algoritmalar ve uygun çekim parametreleri kullanılmalıdır. Hastadan gerekli ve yeterli bilgiyi alabilecek en az dozla çekim yapılabilmelidir (ALARA prensibi).

Bilgisayarlı tomografi (BT) cihazından, otomatik olarak hastanın aldığı radyasyon konsantrasyonu görülebilmektedir. Bu çalışmada, BT cihazının gösterdiği radyasyon konsantrasyonu ile hastanın aldığ 1 gerçek radyasyon konsantrasyonun karşılaştırılması amaçlanmıştır. $\mathrm{Bu}$ amaçla, hasta üzerilerine termolüminesans detektörler (TLD) yerleştirilmiştir. BT cihazından alınan radyasyon sonucu ile TLD ölçümlerinden elde edilen sonuçların tutarlılı̆̆ irdelenmiştir. 


\section{Deneysel çalışmalar}

$\mathrm{Bu}$ çalışmada, cihazlarda bulunan doz azaltma algoritmalarının kullanılarak yapılan çekimlerde cihazın hastanın aldığı dozu gösteren değerler ile hastanın gerçekten aldığı efektif dozu karşılaştırmak amacı ile 25 hasta incelemeye alınmıştır. Hastalardan 2 tanesi kranyum, 4 tanesi kontrastsız üst batın, 4 tanesi kontrastsız tüm batın, 3 tanesi kontrastsız-kontrastlı tüm batın, 2 tanesi kontrastsız çocuk tüm batın, 4 tanesi toraks, 4 tanesi sanal kolonoskopi, 2 tanesi Torakoabdominal anjiyo olmak üzere toplam 46 farklı çekim kullanılmıştır.

Çekim esnasında hastaların çekim bölgeleri üzerine TAEK den alınan hassas doz ölçümü yapan TLD kristali yerleştirilmiştir (Şekil-1). Kristaller yedekleme olması için iki adet alınmıştır. Hastalar iki farklı gruba ayrılmış, kristallerden birisi bir gurba diğeri ise diğer bir gruba konarak çekimler gerçekleştirilmiştir. TLD dozimetrelerinin okuma esnasında problem meydana gelebilme ihtimaline karşı hastalar iki ayrı grupta incelenmiştir. Fakat TLD detektörlerinde herhangi bir problemle karşılaşılmadığ 1 için sonuçlarda her ikisi birleştirilerek verilmiştir.

Çekimlerden hemen sonra cihazın verilerinden DLP değerleri ( Dose Lenght Producht) alınıp her çekim bölgesine uygun dönüşüm faktörleri (kat sayıları) ile çarpılarak hastaların o çekim için aldığı efektif dozlar hesaplanmıştır.

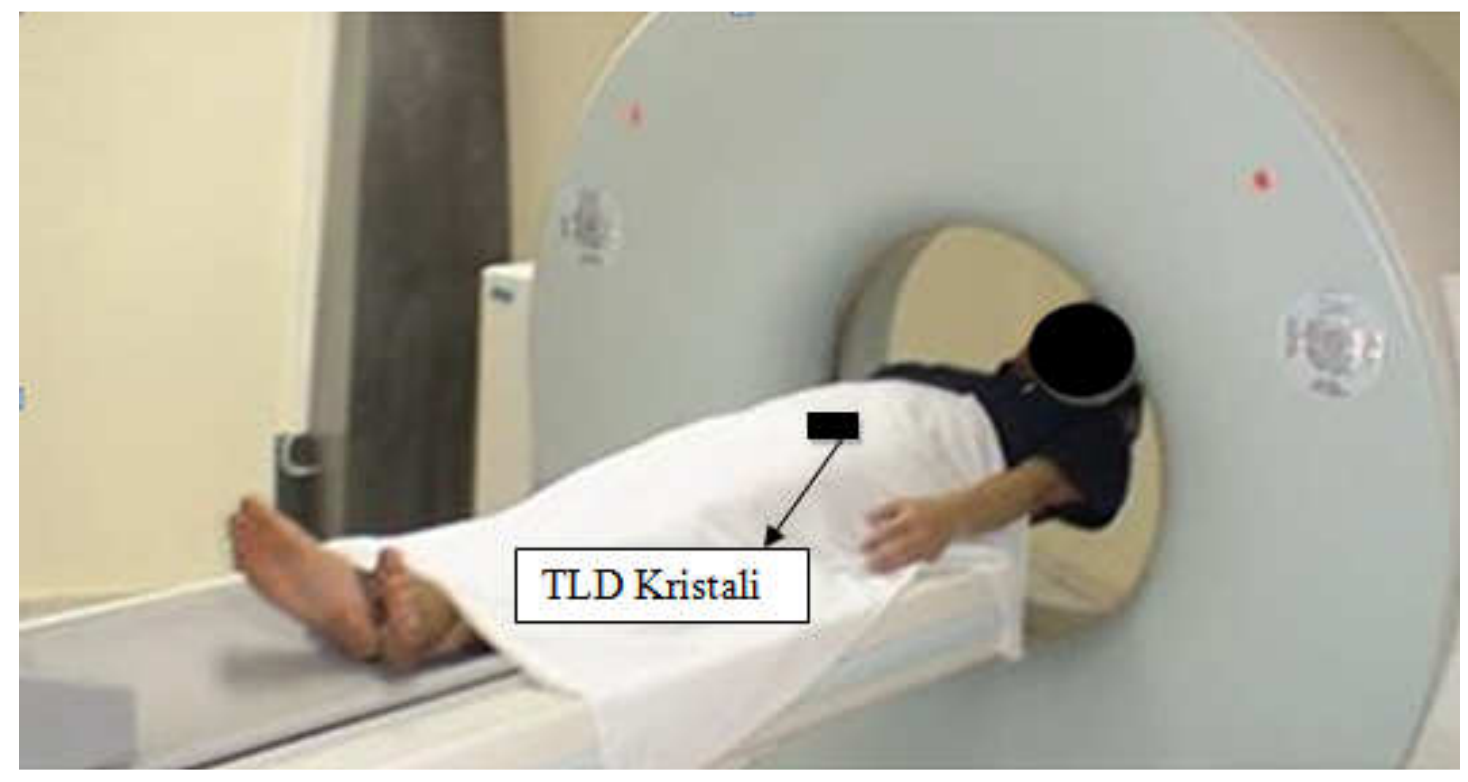

Şekil 1. Batın BT çekiminde TLD kristallerinin lokasyonu

\section{Bulgular ve tartışma}

25 hasta üzerinde yapılan ölçümlerde, her hastanın BT cihazından ölçülen radyasyon efektif dozu tablo 1 de gösterilmiştir. Hastaların tamamının aldığı efektif radyasyon dozunun toplamı 123,543 mSv olarak hesaplanmıştır. Kullanılan TLD kristallerinin numaraları, 0039998 ve 0039999 olup değerlendirmeler Türkiye Atom Enerjisi Kurumu, Sarayköy Nükleer Araştırma Merkezi Sağlık fiziği bölümü tarafından değerlendirilmiştir. TLD kristallerinin hastaya yerleştirilmesi ve TAEK tarafından 
değerlendirilmesi sonucunda tüm hastaların aldığı toplam efektif radyasyon dozunun $128.62 \mathrm{mSv}$ olduğu görülmüştür.

Bir hastanın belirli bir BT çekiminde alması gereken tahmini doz ED (Estimated Dose) orak tanımlanır. Herhangi bir organın X 1şını absorbe edebileceği değer katsayına dönüşüm faktörü (DF) denir. DLP (Dose Length Product), Bt incelenmesinde belirli bir uzunlukta alınan toplam radyasyon dozu miktarıdır.

Bilgisayarlı tomografi cihazından elde edilen tahmini doz;

\section{$\mathrm{ED}=\mathrm{DF} * \mathrm{DLP}$}

bağıntısıyla bulunur.

Burada;

ED: Tahmini doz

DF: Dönüşü̈m Faktörü

DLP: Belirli çekim uzunluğunda ve süresinde alınan doz olarak verilmiştir.

Amerika Tıp Fizikçileri Derneğinin (American Associaton of Physicist in Medicine), 2008 yılındaki 96 numaralı raporunda, bilgisayarlı tomografide yaygın radyolojik çekimlerde beklenen etkin doz değerleri(Tablo 2) yayınlanmıştır [20]. Bu rapordaki hastaların her bir çekim bölgesinden aldığı radyasyon doz değerleri ve bu değerlerin toplamı, TLD kristallerinden TAEK tarafından ölçülen değerler literatürle uyum içinde olduğu görülmüştür.

Tablo 1. Bilgisayarlı Tomografiden elde edilen hastaya ait görüntüleme parametreleri ve radyasyon dozları.

\begin{tabular}{|l|l|l|l|c|c|c|c|l|l|}
\hline $\begin{array}{c}\text { Hasta } \\
\text { No }\end{array}$ & $\mathrm{kV}$ & $\mathrm{mA}$ & $\begin{array}{c}\text { Fov } \\
(\mathrm{cm})\end{array}$ & $\begin{array}{c}\text { Çekilen } \\
\text { Alan } \\
\text { Uzunluğu } \\
(\mathrm{cm})\end{array}$ & $\begin{array}{c}\text { Çekim } \\
\text { Süresi } \\
(\mathrm{s})\end{array}$ & $\begin{array}{c}\text { DLP } \\
(\mathrm{mSv}-\mathrm{cm})\end{array}$ & $\begin{array}{c}\text { Dönüşüm } \\
\text { Faktörü } \\
(\mathrm{DF})\end{array}$ & $\begin{array}{c}\text { Alınan } \\
\text { Doz } \\
(\mathrm{mSv})\end{array}$ & $\begin{array}{l}\text { Çekim } \\
\text { Bölgesi }\end{array}$ \\
\hline 1 Hasta & 120 & $\mathrm{O}$ & 36 & 50 & 8 & 240,74 & 0,0190 & 4,574 & Üst Batın \\
\hline 2 Hasta & 120 & $\mathrm{O}$ & 15 & 8 & 3 & 954,44 & 0,0023 & 2,195 & Kranyum \\
\hline 3 Hasta & 120 & $\mathrm{O}$ & 15 & 8 & 3 & 954,44 & 0,0023 & 2,195 & Kranyum \\
\hline 4 Hasta & 120 & $\mathrm{O}$ & 36 & 40 & 8 & 181,97 & 0,0190 & 3,457 & Üst Batın \\
\hline 5 Hasta & 120 & $\mathrm{O}$ & 36 & 31 & 5 & 132,59 & 0,0190 & 2,519 & Üst Batın \\
\hline 6 Hasta & 120 & $\mathrm{O}$ & 36 & 30 & 5 & 92,96 & 0,0170 & 1,580 & Toraks \\
\hline 7 Hasta & 120 & $\mathrm{O}$ & 36 & 30 & 4 & 136,24 & 0,0190 & 2,589 & Üst Batın \\
\hline 8 Hasta & 120 & $\mathrm{O}$ & 36 & 62 & 8 & 428,32 & 0,0190 & 8,138 & $\begin{array}{l}\text { Tüm Batın } \\
\text { Klı ve Ksız }\end{array}$ \\
\hline 9 Hasta & 120 & $\mathrm{O}$ & 36 & 15 & 2 & 431,95 & 0,0190 & 8,207 & $\begin{array}{l}\text { Tüm Batın } \\
\text { Klı ve Ksız }\end{array}$ \\
\hline 10 Hasta & 120 & $\mathrm{O}$ & 36 & 62 & 8 & 626,52 & 0,0190 & 11,904 & T. A.Anjiyo \\
\hline 11 Hasta & 120 & $\mathrm{O}$ & 36 & 40 & 5 & 149,35 & 0,0190 & 2,838 & Tüm Batın \\
\hline 12 Hasta & 120 & $\mathrm{O}$ & 36 & 62 & 8 & 606,86 & 0,0190 & 11,530 & T. A.Anjiyo \\
\hline 13 Hasta & 120 & $\mathrm{O}$ & 43 & 44 & 5 & 236,27 & 0,0190 & 4,489 & Tüm Batın \\
\hline 14 Hasta & 120 & $\mathrm{O}$ & 45 & 46 & 5 & 607,00 & 0,0190 & 11,533 & $\begin{array}{l}\text { Tüm Batın } \\
\text { Klı ve Ksız }\end{array}$ \\
\hline 15 Hasta & 120 & $\mathrm{O}$ & 36 & 41 & 4 & 145,06 & 0,0190 & 2,756 & Tüm Batın \\
\hline 16 Hasta & 120 & $\mathrm{O}$ & 36 & 54 & 6 & 264,87 & 0,0190 & 5,033 & Tüm Batın \\
\hline
\end{tabular}


Tablo 1. (Devam1).

\begin{tabular}{|l|l|l|l|l|l|l|l|l|l|}
\hline 17 Hasta & 120 & $\mathrm{O}$ & 36 & 12 & 2 & 41,40 & 0,0170 & 0,704 & Toraks \\
\hline 18 Hasta & 120 & $\mathrm{O}$ & 36 & 61 & 4 & 493,83 & 0,0190 & 9,383 & Tüm Batın \\
\hline 19 Hasta & 120 & $\mathrm{O}$ & 36 & 35 & 3 & 191,96 & 0,0170 & 3,263 & Toraks \\
\hline 20 Hasta & 120 & $\mathrm{O}$ & 36 & 44 & 4 & 258,85 & 0,0190 & 4,918 & $\begin{array}{l}\text { Sanal } \\
\text { Kolonoskopi }\end{array}$ \\
\hline 21 Hasta & 120 & $\mathrm{O}$ & 36 & 47 & 4 & 241,19 & 0,0190 & 4,583 & $\begin{array}{l}\text { Sanal } \\
\text { Kolonoskopi }\end{array}$ \\
\hline 22 Hasta & 120 & $\mathrm{O}$ & 36 & 44 & 4 & 256,67 & 0,0190 & 4,877 & $\begin{array}{l}\text { Sanal } \\
\text { Kolonoskopi }\end{array}$ \\
\hline 23 Hasta & 120 & $\mathrm{O}$ & 36 & 43 & 4 & 220,41 & 0,0190 & 4,188 & $\begin{array}{l}\text { Sanal } \\
\text { Kolonoskopi }\end{array}$ \\
\hline 24 Hasta & 120 & $\mathrm{O}$ & 36 & 30 & 3 & 79,13 & 0,0170 & 1,345 & Toraks \\
\hline 25 Hasta & 120 & $\mathrm{O}$ & 36 & 50 & 5 & 249,77 & 0,0190 & 4,746 & Tüm Batın \\
\hline Toplam & & & & & & & & 123,543 & \\
\hline
\end{tabular}

O : Otomatik

Klı : :Kontrastlı

Ksiz : Kontrastsiz

Tablo 2. Bilgisayarlı tomografide yaygın radyolojik çekimlerde beklenen etkin doz değerleri

\begin{tabular}{|c|c|}
\hline $\begin{array}{c}\text { Bilgisayarlı Tomografi } \\
\text { Çekim türü }\end{array}$ & $\begin{array}{c}\text { Efektif Radyasyon Dozu } \\
\text { (mSv) }\end{array}$ \\
\hline Kranyal BT & $1-2$ \\
\hline Toraks BT & $5-7$ \\
\hline Abdomen BT & $5-7$ \\
\hline Pelvis BT & $3-4$ \\
\hline Üst ve Alt Batın BT & $8-14$ \\
\hline $\begin{array}{c}\text { Koroner Arter Kalsiyum } \\
\text { Skorlama }\end{array}$ & $1-3$ \\
\hline Koroner Arter Anjiyografi & $5-15$ \\
\hline
\end{tabular}

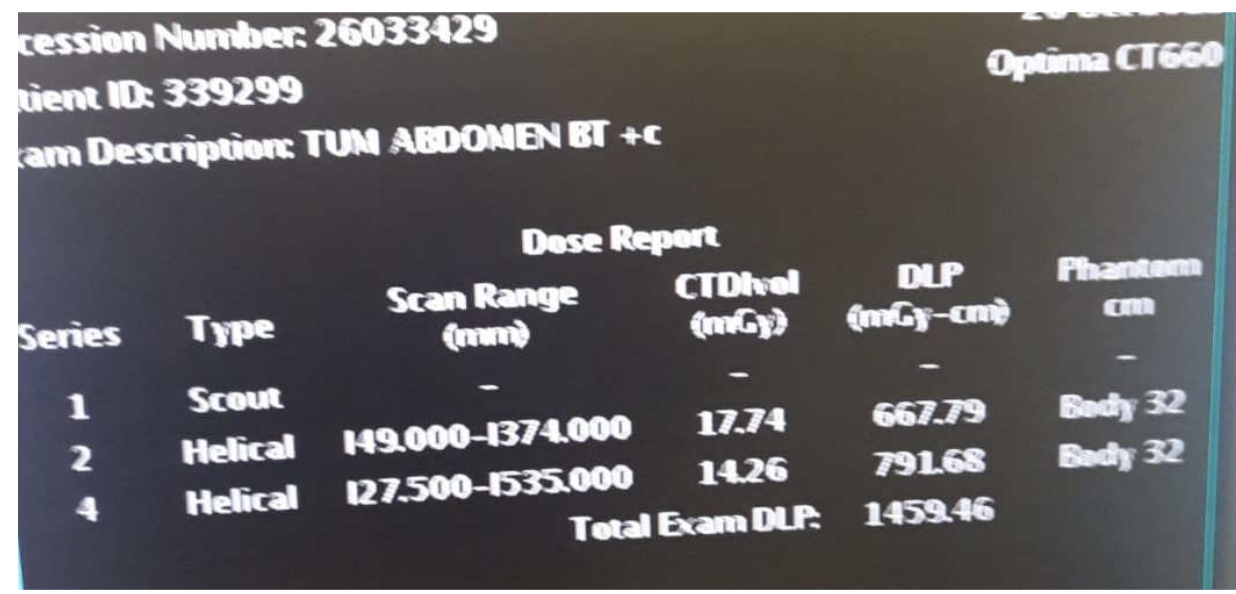

Şekil 2. BT cihazından görülen DLP değerleri ekran görüntüsü örneği. 
ASİR programı kullanılmadan yapılan BT çekimlerinde hastanın aldığı radyasyon dozunun daha yüksek olduğu bulunmuştur. Şekil 2 de ASİR programı kullanılmadan yapılan BT çekimlerinin ekran görüntüsünde DLP değerleri görülmektedir. Bu değerler kullanılarak hastanın aldığı radyasyon dozu hesaplanmıştır. ASİR programı kullanılmadan aynı cihazda aynı bölgede ve aynı özellikteki çekimlerde örneğin toraks tek çekim $6.66 \mathrm{mSv}$ bulunmuşken ASIR programı kullanıldığında $1.58 \mathrm{mSv}$ ve 3.26 mSv olarak bulunmuştur. Tüm batın kontrastlı ve kontrastsız çekimlerde ise, ASİR programı kullanılmadan $27.79 \mathrm{mSv}$ olurken, ASİR programı kullanıldığında $8.13 \mathrm{mSv}$ ve $11.53 \mathrm{mSv}$ arasında bulunmuştur.

\section{Sonuç}

25 hasta üzerinde yapılan ölçümlerde, BT cihazından ölçülen toplam efektif dozun $123,543 \mathrm{mSv}$ olduğu hesaplanmıștır. TLD kristallerinin hastaya yerleștirilmesi ve TAEK tarafından değerlendirilmesi sonucunda tüm hastaların aldığı toplam efektif radyasyon dozunun $128.62 \mathrm{mSv}$ olduğu ölçülmüştür. BT cihazından elde edilen sonuçlarla TAEK' den alınan TLD sonuçları karşılaştırıldığında \%4 gibi çok az bir fark bulunmuştur.

ASİR programı kullanılan BT çekimlerinde, her hasta için hesaplanan ve hastaların aldığı toplam dozların literatürde beklenen ve kabul edilebilir sınırlarda olduğu saptanmıştır. ASİR programı kullanılmadan yapılan çekimlerde ise hastaların daha yüksek radyasyona maruz kaldığı görülmüsstür. Dolayısıyla, cihazın doz azaltma yazılımı olan ASİR (Adaptive Statistical Iterative Reconstruction) programının da şirketçe lanse edildiği gibi çalıştığı saptanmıştır.

\section{Kaynaklar}

[1] Yarar, O., Temizsoy, E. ve Günay, O., Noise pollution level in a pediatric hospital, International Journal of Environmental Scienceand Technology, 16, (2018).

[2] Aközcan, S., Annual effective dose of naturally occurring radionuclides in soil and sediment, Toxicologycal and Environmental Chemistry, 96.3, 379-386, (2014).

[3] Çetin, B., Öner F. ve Akkurt I., Determination of natural radioactivity and associated radiological hazard in excavation field in Turkey (OluzHöyük), Acta Physica Polonica A, 130(1), 475-478, (2016).

[4] Günay, O., Determination of natural radioactivity and radiological effects in some soil samples in Beykoz-Istanbul, European Journal of Science and Technology, 12, 9-14, (2018).

[5] Günay, O., Saç, M.M., Içhedef, M. ve Taşköprü, C., Natural radioactivity analysis of soil samples from Ganos fault (GF), International Journal of Environmental Science and Technology, 1-4., (2018).

[6] Aközcan, S., Y1lmaz, M. ve Külahc1 F., Dose rate and seasonal variations of ${ }^{238} \mathrm{U},{ }^{232} \mathrm{Th},{ }^{226} \mathrm{Ra},{ }^{40} \mathrm{~K}$ and ${ }^{137} \mathrm{Cs}$ radionuclides in soils along Thrace, Turkey, Journal of Radioanalytical and Nuclear Chemistry, 299(1), 95-101, (2014).

[7] Günay, O., Saç, M.M., Içhedef, M. ve Taşköprü, C., Soil gas radon concentrations along the Ganos Fault (GF), Arabian Journal of Geosciences, 11(9), 213, (2018). 
[8] Korkulu, Z. ve Özkan N., Determination of natural radioactivity levels of beachs and samples in the blacksea coast of Kocaeli (Turkey), Radiation Physics and Chemistry, 88, 27-31, (2013).

[9] Mavi, B. ve Akkurt, I., Natural radioactivity and radiation hazards in some building materials used in Isparta, Turkey, Radiation Physics and Chemistry, 79(9), 933-937, (2010).

[10] Seçkiner, S., Akkurt, I., Günoglu K., Determination of ${ }^{40} \mathrm{~K}$ concentration in gravel samples from Konyaaltı Beach, Antalya, Acta Physica Polonica A, 132(3). 1095-1097, (2017).

[11] Uyanık N.A., Uyanık O. ve Akkurt I., Micro-zoning of the natural radioactivity levels and seismic velocities of potential residential areas in volcanic fields: Thecase of Isparta (Turkey), Journal of Applied Geophysics, 98, 191-204, (2013)

[12] Kara, U., Kaya A., Tekin H.O. ve Akkurt I., Adult patient radiation doses with multislice computed tomography exam: MSCT standard protocols, Acta Physica Polonica A, 132, 3, 1126-1127, (2017).

[13] Mitelman, F., Johansson, B. ve Mertens, F., The impact of translocations and gene fusions on cancer causation, Nature Reviews Cancer, 7(4), 233, (2007)

[14] Hall, E. J. ve Brenner, D. J., Cancer risks from diagnostic radiology, The British Journal of Radiology, 81(965), 362-378, (2008).

[15] Rezak, A., Abbas, H. M., Ajemian, M. S., Dudrick, S. J. ve Kwasnik, E. M., Decreased use of computed tomography with a modified clinical scoring system in diagnosis of pediatric acute appendicitis, Archives of Surgery, 146(1), 64-67, (2011).

[16] Mettler Jr, F.A., Wiest, P.W., Locken, J.A. ve Kelsey, C.A., CT scanning: patterns of use and dose, Journal of radiological Protection, 20(4), 353, (2000).

[17] White, K. S., Invited article: helical/spiral CT scanning: a pediatric radiology perspective, Pediatric radiology, 26(1), 5-14, (1996).

[18] Linton, O.W. ve Mettler Jr, F.A., National conference on dose reduction in CT, with an emphasis on pediatric patients. American Journal of Roentgenology, 181(2), 321-329, (2003).

[19] Brenner, D.J. ve Elliston, C.D., Estimated radiation risks potentially associated with full-body CT screening, Radiology, 232:735-8, (2004).

[20] American Associaton of Physicist in Medicine, The Measurement, Reporting, and Management of Radiation Dose in CT, Aapm Report No, 96, (2008). 